Journal of Engineering and Applied Sciences 15 (5): 1228-1236, 2020

ISSN: 1816-949X

(C) Medwell Journals, 2020

\title{
Impact of Potential Evapotranspiration Method on Sensitivity and Uncertainty in Streamflow Analysis for Kelantan River Basin
}

\author{
${ }^{1,2}$ Mohd Khardzir Husain, ${ }^{4}$ Gasim Hayder, ${ }^{3,4}$ Lariyah Mohd Sidek, ${ }^{3,4}$ Ali Najah Ahmed \\ ${ }^{1}$ College of Graduate Studies, Universiti Tenaga Nasional (UNITEN), \\ 43000 Kajang, Selangor, Malaysia \\ ${ }^{2}$ Department of Irrigation and Drainage, 50626 Kuala Lumpur, Malaysia \\ ${ }^{3}$ Institute of Energy Infrastructure (IEI), Universiti Tenaga Nasional (UNITEN), \\ 43000 Kajang, Selangor, Malaysia \\ ${ }^{4}$ Department of Civil Engineering, College of Engineering, Universiti Tenaga Nasional, \\ 43000 Kajang, Selangor, Malaysia
}

\begin{abstract}
Range of sensitive parameter value associated with uncertainty should be performed in the calibration and validation process to establish more accurate watershed hydrological models. Evapotranspiration is one of the most dominant in a hydrological cycle other than surface runoff and subsurface processes. This research aims at an in-depth understanding of the SWAT-CUP ability on analyzing the impact of Potential Evapotranspiration (PET) methods on sensitive parameter and uncertainty streamflow simulations of the Kelantan river basin. The hydrological model was developed using the SWAT with three option of PET methods: Penman-Monteith (P-M), Priestley-Taylor (P-T) and Hargreaves (HG). The SWAT-CUP with SUFI-2 optimization algorithm and Nash-Sutcliffe as objective function were used to evaluate the model simulation compared to the streamflow discharge from years 1985-2000 for calibration and 2001-2016 for validation periods. The best value of NSE, R2 and PBIAS, indicated no significant difference and the model achieved very good performance during calibration and good performance during validation. The 95PPU plot and statistics value, $\mathrm{p}$-factor yielded acceptable outcomes during calibration by bracketing of the observed streamflow data with 82,74 and $75 \%$ for HG, P-T and P-M, respectively. However, the p-factor was achieved only 46, 40 and $44 \%$, respectively during the validation period. The calibration strength of the r-factor was reached with HG $(0.75,0.67)$, P-T $(0.92,0.84)$ and P-M $(0.88,0.81)$ during calibration and validation. The uncertainty analysis showed that P-T is better performer during both the calibration and validation. Overall the SWAT Model was considered can give good performance with the built-in PET methods options.
\end{abstract}

$\underline{\text { Key words: SWAT-CUP, SUFI-2, potential evapotranspiration, uncertainty, sensitive parameter, streamflow }}$

\section{INTRODUCTION}

Evaluation of a hydrological model performance through parameters sensitivity test and model uncertainty analysis is a critical measure to verify the model strength. Regular model evaluation by using the basic statistic of the determination coefficient (R2), Nash-Sutcliffe Efficiency (NSE) and Percent Bias (PBIAS) was insufficient to assess the fit and model correlation. In addition, the 95PPU analysis by the value of $\mathrm{p}$-factor and $r$-factor should be considered to have the degree of uncertainty and sensitivity of the optimized parameter values for a site-specific. NSE, R2, PBIAS, p-factor and $\mathrm{r}$-factor will enhance the calibration and validation process to have a good model. A well-calibrated model will able to describe and simulate the hydrological processes for any forecast situations in more precise and sufficient accurate as of the real situation (Kannan et al., 2019; Querner and Zanen, 2013).

Nowadays, the Soil and Water Assessment Tool (SWAT) has been proven to be a useful hydrological model for the watershed assessment of water quantity and quality (Qi et al., 2009; Querner and Zanen, 2013; Thavhana et al., 2018), sediment and nutrient transport (Dakhlalla and Parajuli, 2018; Megersa et al., 2019), future effect of land management (Ayivi and Tha, 2018; Zhang et al., 2017), potential climate change impacts (Bekele et al., 2019; Zhao et al., 2019) and valuation ecological problems (Sun et al., 2017; Vigiak et al., 2018). The SWAT is integrated with Arc-GIS as an extension to have semi-distributed and continuous long-term simulation model which reflects various of physical processes included portioning into sub-watersheds, hydrologic cycle (precipitation, evaporation and transpiration, potential evapotranspiration, infiltration, lateral flow, percolation, recharge to aquifer, return flow, surface runoff), pesticides and nutrient cycle (nitrogen and phosphorus) and erosion and sedimentation (Neitsch et al., 2011).

The SWAT Model has incorporated more than 250 parameters with a set of pre-defined parameter

Corresponding Author: Mohd Khardzir Husain, College of Graduate Studies, Universiti Tenaga Nasional (UNITEN), 43000 Kajang, Selangor, Malaysia 
value cover soils properties, surface runoff, infiltration, percolation, evaporation and evapotranspiration. Range of sensitive parameter value associated with uncertainty should be performed in the calibration and validation process to establish more accurate watershed hydrological models. Evapotranspiration is one of the most dominant in a hydrological cycle other than surface runoff and subsurface processes. Potential Evapotranspiration (PET) is referring to the possible highest volume of evaporation water and transpiration from the vegetated surface under standard soil moisture and vegetation conditions with unlimited water supply due to the prevailing meteorological conditions. The PET in a watershed ecosystem directly influences the hydrological cycle and energy balance which can disturb the dynamics of soil content storage, groundwater physical properties and streamflow discharge (Dinpashoh et al., 2019).

The SWAT Model offer with four calculations methods available within SWAT for PET calculation: Penman-Monteith (P-M), Priestley-Taylor (P-T), Hargreaves $(\mathrm{HG})$ and the user defines (Neitsch et al., 2011). However, the available built-in methods estimate varying values due to their development process consider for a specific climatic region with a different perspective, assumptions and input data requirements (Alemayehu et al., 2015). The data requirements for PET calculation is varying for each selected methods. The Penman-Monteith method involves information of daily solar radiation, minimum and maximum air temperature, relative humidity and wind speed. The Priestley-Taylor method is an empirical approach of P-M where only needs radiation of solar, temperature of air and relative humidity. Relative humidity is required for vapor pressure calculation in P-M and P-T methods. While the Hargreaves method depending only on the mean, maximum and minimum of air temperature. This method is desirable in the case missing data either the wind speed, solar radiation or relative humidity (Efthimiou et al., 2013).

\section{MATERIALS AND METHODS}

Study area: The SWAT Model was applied to the Kelantan river basin at the Guillemard Bridge discharge station, covering an area of $12,600 \mathrm{~km}^{2}$ with the lowest elevation of $1.1 \mathrm{~m}$ and the highest elevation of $2,159.9 \mathrm{~m}$ (Fig. 1a). The total stretches length is $514 \mathrm{~km}$ included the main tributaries of Lebir river, Galas river and Pergau river with the longest path is $273 \mathrm{~km}$ from the most upstream. The station is located to the Northwards of Kelantan river about $65 \mathrm{~km}$ to the river mouth. The area received annual average rainfall is about $2,500 \mathrm{~mm}$. Fig. 1b shows the Guillemard Bridge Watershed (GBW) land use which was predominated by forest at the upstream and midstream, occupying approximately $76 \%$, agriculture activity (rubber, oil palm, coconut, etc.) was $23 \%$ in the middle and downstream of the catchment. There was $<1 \%$ development used for residential, commercial and industrial.

SWAT Model setup: Guillemard Bridge Watershed hydrological model was established using the SWAT Model (Neitsch et al., 2011). The applications integrate the watershed spatial data (Digital Elevation Model (DEM), soil and land used) with daily climatic variables data (precipitation ( $\mathrm{mm}$ ), evaporation ( $\mathrm{mm}$ ), air temperature $\left({ }^{\circ} \mathrm{C}\right)$, relative humidity, wind speed and solar radiation) for the modeling. Historical rainfall data from years 1980-2016 in daily time-series format were derived from 16 stations within the GBW. While the daily observed streamflow discharge from 1985-2016 at Guillemard Bridge station (Fig. 1) was divided to years 1985-2000, for calibration and 2001-2016 for validation. The DEM $5 \mathrm{~m}$ resolution of Interferometric Synthetic Aperture Radar (IFSAR) was used for topography elevation data and classification map was used to represent the land use data for the year 2010.

The DEM integrated with soil and land use, slope classes options $(0-15,15-24,24-35,35-49$ and $>49 \%)$ and threshold values of $10 \%$ for soil, $20 \%$ for land used and slope were discretized by ArcGIS to smaller spatial sub-units (Her et al., 2015; Megersa et al., 2019; Yacoub and Foguet, 2012). Based on these spatial pieces of information, 29 sub-watersheds was created with 224 Hydrological Response Units (HRU). The HRUsre main the homogeneous and contains combinations of soil properties, land used type, slope features and land management in the watershed. The elevation at the outlet of the sub-basin 2 (Guillemard Bridge station) represents the reference low points in the mainstream. Surface water originating from the sub-watersheds eventually accumulate at low points to represents as a tributary stream in each sub-watersheds and leaves to join into the mainstream ofthe Kelantan river (Chunn et al., 2019).

Model calibration and sensitivity analysis: We recently conducted the parameters sensitivity analysis, calibration, validation and uncertainty analysis of SWAT Models by using the SWAT Calibration and Uncertainty Programs (SWAT-CUP) (Abbaspour, 2015). We had chosen the SUFI-2 option with objective function NSE 0.5 and selected parameters for the model sensitivity analysis. The parameters which being considered to have influential on streamflow discharge based on knowledge of a catchment and those suggested in the reference literatures (Ayivi and Jha, 2018; Bekele et al., 2019; Ligaray et al., 2015; Maharjan et al., 2013; Narsimlu et al., 2015; Tan et al., 2014; Thavhana etal., 2018). 


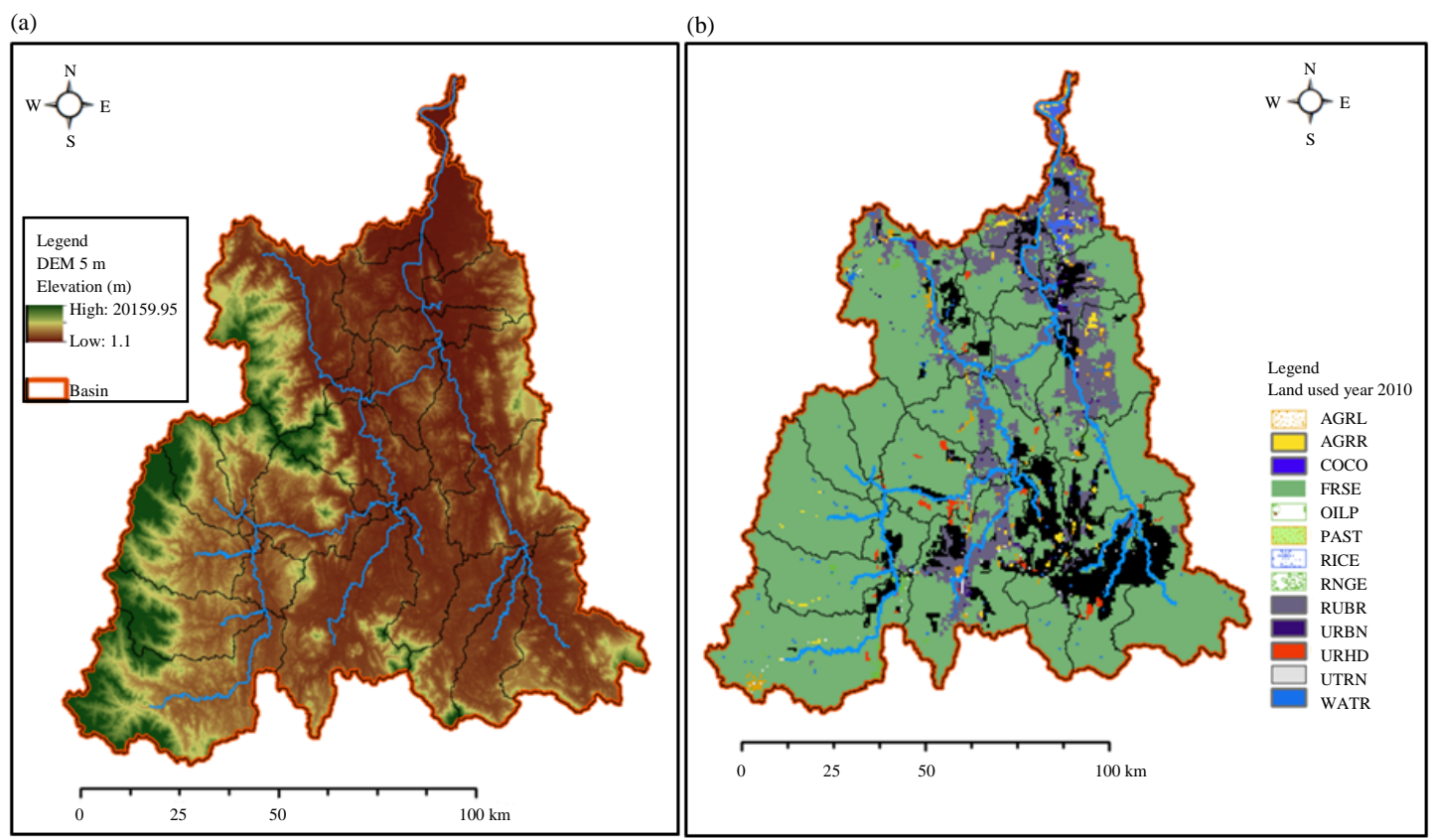

Fig. 1(a-b): (a) Topographical view of DEM $5 \mathrm{~m}$ with the network of main and tributaries rivers in the Guillemard Bridge watershed and (b) Guillemard Bridge sub-basin and land use for the year 2010
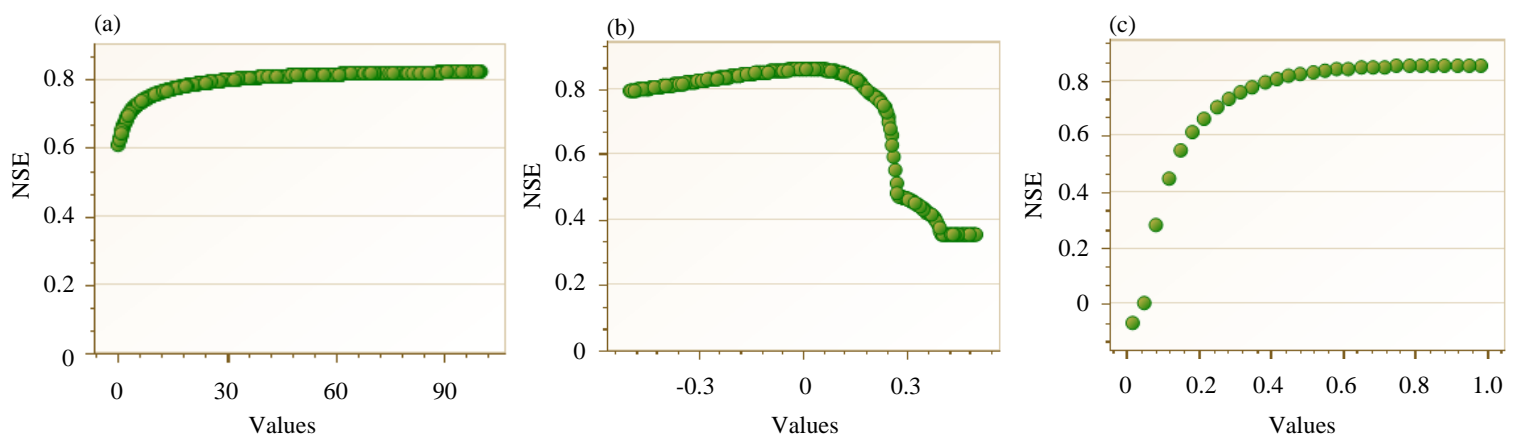

Fig. 2(a-c): Results of local analysis dotty plot with the objective function of NSE for the streamflow most sensitive parameters (a) 1: CANMX.hru, (b) 1: CN2.mgt and (c) 1: ALPHA_BNK.rte

At the early stage, local sensitivity analysis for 29 parameters was performed to identify the governing flow factors through the SWAT-CUP output of the dotty plot (Narsimlu et al., 2015). The local sensitivity analysis or one-factor-at-a-time demonstrates the sensitiveness of model performance with the change of a variable input value when other parameters are kept constant as drown in Fig. 2 and 3 (Khalid et al., 2016). Then, the significance of the parameter sensitivity and ranking among the selected parameter were identified for the three PET SWAT Models based on global sensitivity analysis (Abbaspour, 2015).

The calibration procedure starts by providing a large range based on default parameters value as the initial parameter range. The calibration algorithms run with varied iteratively values and narrows down the range until the best parameter range is obtained with an optimal agreement between observation and simulation (Samadi et al., 2017). In each iteration, the SUFI-2 algorithm performs Latin Hypercube sampling for user-defined parameter ranges and creates multiple parameter set samples.

The SWAT-CUP was run with the 22 selected sensitive parameters for a few iterations during calibration until the defined objective function was satisfied and each iteration was set for 500 simulation runs. Later, the values range for each parameter were updated and each new ranges were smaller than the initial range. The parameter 
(a)

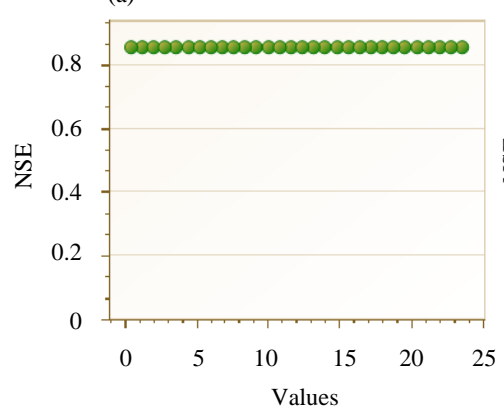

(b)

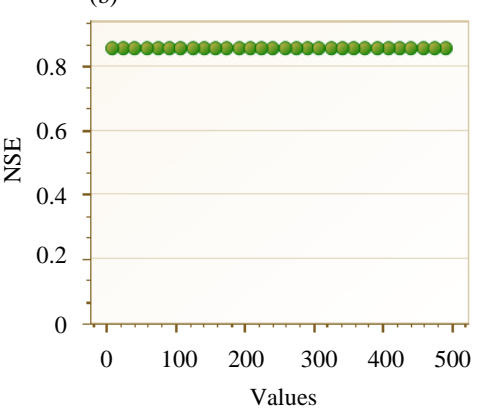

(c)

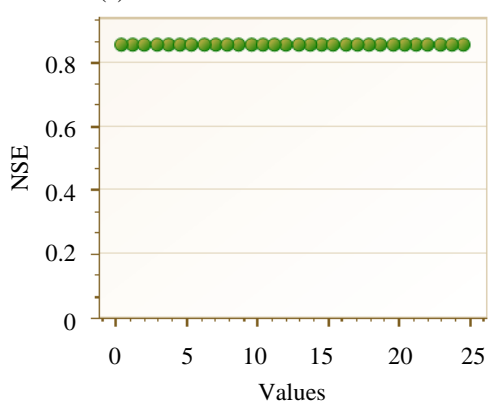

Fig. 3(a-c): The dotty plot for streamflow insensitive parameters (a) 1: SURLAG.bsn, (b) 1: REVAPMN.gw and (c) 1: GWHT.gw

Table 1: The statistical evaluation criteria for monthly streamflow models performance

\begin{tabular}{lllll}
\hline Statistical criteria & Very good & Good & Satisfactory & Unsatisfactory \\
\hline $\mathrm{R}^{2}$ & $\mathrm{R}^{2}>0.85$ & $0.75<\mathrm{R}^{2} \leq 0.85$ & $0.60<\mathrm{R}^{2} \leq 0.75$ & $\mathrm{R}^{2} \leq 0.6$ \\
NSE & NSE $>0.80$ & $0.70<\mathrm{NSE} \leq 0.80$ & $0.50<\mathrm{NSE} \leq 0.70$ & NSE $\leq 0.50$ \\
PBIAS & PBIAS $< \pm 5$ & $\pm 5 \leq \mathrm{PBIAS}< \pm 10$ & $\pm 10 \leq \mathrm{PBIAS}< \pm 15$ & PBIAS $\geq \pm 15$ \\
p-factor & p-factor $>0.70$ & & p-factor $\leq 0.70$ & \\
r-factor & r-factor $<1.5$ & & $1.5 \leq \mathrm{r}$-factor & \\
\hline
\end{tabular}

ranges get thinner through the iterations until the best performing parameter range is obtained. Afterward, the ranges of the parameters with the better performance results were used for the validation process.

Model performance evaluation: The SWAT-CUP compares the best simulation from the SUFI-2 with the observed discharge and computes the statistical measures. In this study, the model performance was evaluated based on the Nash-Sutcliffe coefficient (NSE), coefficient of determination $\left(\mathrm{R}^{2}\right)$ and Percent BIAS (PBIAS). Furthermore, the 95PPU indicator of p-factor and r-factor was used to measure the degree of the model uncertainties. The p-factor is the percentage of the observations data are bracketed within the 95PPU and denoted by an ideal value of $100 \%$ where all the quantifies uncertainties were in the shaded region of the simulation results by the parameter range. The degree of uncertainty, $\mathrm{r}$-factor is the average distance between the 95PPU and the standard deviation of the observed variables (Abbaspour, 2015). The evaluations of the model performance were based on recommended by the works of literature as shown in Table 1 (Abbaspour et al., 2015; Paul and Negahban-Azar, 2018).

\section{RESULTS AND DISCUSSION}

Streamflow sensitivity parameter: The local analysis has confirmed that the 22 out of 29 parameters were found are sensitive and considered to be appropriate for Guillemard Bridge Watershed Model for all the three PET methods. SUFI-2 uses a multiple regression and the significant parameters that highly influences on the streamflow simulations represent by $\mathrm{p}$-value and t-stat. The parameters with the smallest p-values close to zero $(<0.05)$ indicate to be meaningful and have a high level of significance to the model and larger in absolute t-stat values are more significance sensitive (Samadi et al., 2017). Table 2 illustrates the rank of the 22 sensitive parameters selected and their optimize value obtained in the calibration process using SWAT-CUP. The p-value and t-stat were fluctuating from $0.00-0.97$ and -13.19 to 4.51 (P-T), $0.00-0.91$ and -12.49 to 3.41 (P-M) and 0.00 to 0.88 and -20.97 to $25.82(\mathrm{HG})$, respectively. The GWQMN ( $\left.\mathrm{mm} \mathrm{H}_{2} \mathrm{O}\right)$ is a parameter that related to the sub-base water flowing from the shallow aquifer to the river at the certain range of aquifer depth only was sensitive while use P-M method.

CANMX $\left(\mathrm{mm} \mathrm{H}_{2} \mathrm{O}\right)$ is one of the sensitive land cover features of a basin that should be calibrated independently and the values fed-in at each HRUs before further calibration with other sensitive parameters. The CANMX is related to the amount of precipitation that can be trapped in the form of droplets on the canopy and affect the evapotranspiration. The parameters values vary from 0.25-75 depending on the selection of PET estimation methods (Table 2). The lowest values were optimized by models that use the HG method and the fitted values by P-T method was five. On the other hand, the highest value was fitted by the model with P-M method as well as the finding by Alemayehu et al. (2015) where the higher values are obtained for models that apply P-M method.

The sensitive parameters rank for the watershed generally varies with the difference PET estimation methods and divided to significant sensitive for the first 
J. Eng. Applied Sci., 15 (5): 1228-1236, 2020

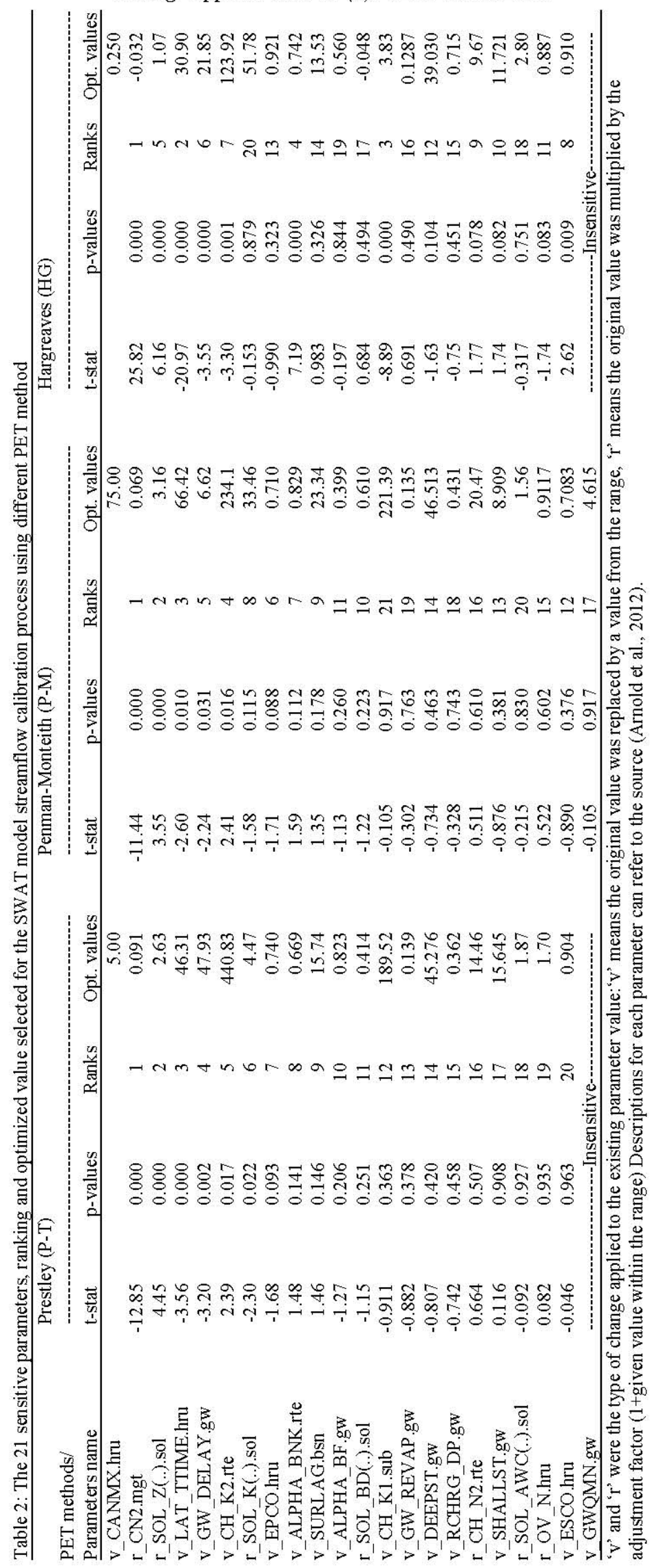



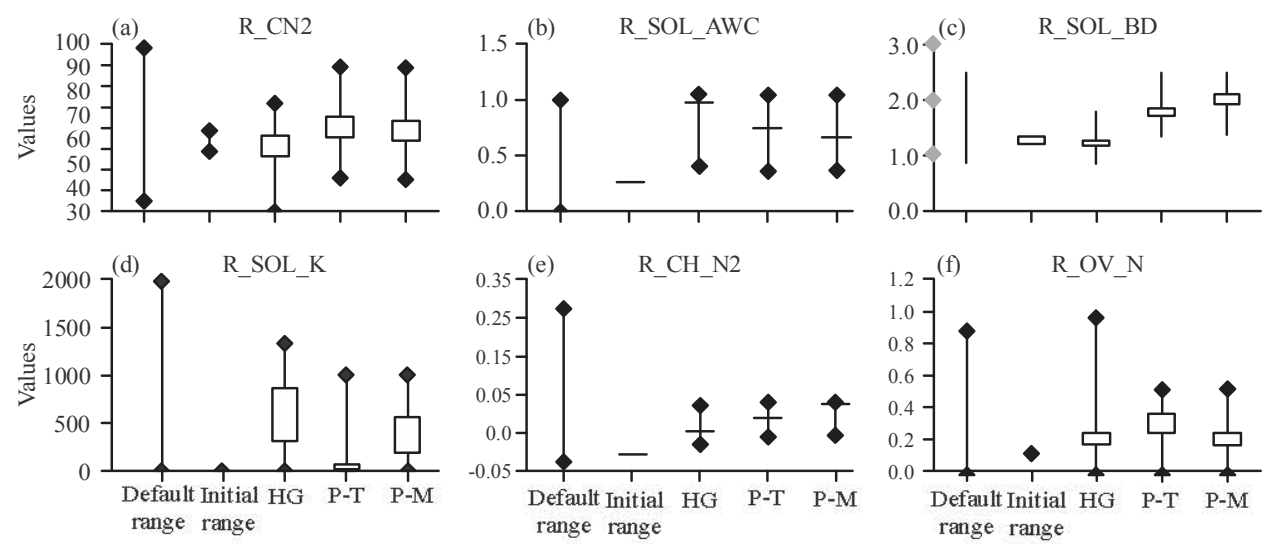

Fig. 4(a-f): The final ranges and optimize value with ' $r$ ' adjustment for the sensitive streamflow parameters (a) CN2.mgt, (b) SOL_K.sol, (c) SOL_AWC.sol, (d) SOL_BD.sol, (e) OV_N.hru and (f) CH_N2.rte

ten and others considered insignificant sensitive. These results suggest that the most significance sensitive parameters were kept the same ranks due to the same climate and topography data. Almost of the parameters mainly have direct effect to the sub-surface water generation of lateral and return flow (ALPHA_BF, GW REVAP, DEEPST, RCHRG DP, SHALL̄ST, LAT_TIME, SOL_Z, SOL_AWC, SOL_K and SOL_BD), to the channel flow (ALPHA_BNK, CH_K2, CH_N2 and $\left.\mathrm{CH} \_\mathrm{K} 1\right)$ and to the surface runoff ( $\overline{\mathrm{CN}} 2$, CANMX, EPCO, ESCO, SURLAG and OV_N). Among those, there was agreed that the CN2 (SCS runoff curve number), the SOL Z (depth of bottom layer to soil surface) andLAT_TIME (Lateral Flow travel Time) were most sensitive for the PET methods. Whereas the $\mathrm{CH}_{-} \mathrm{K} 1$ (hydraulic conductivity in tributary channel alluvium) only showed significant sensitive with $\mathrm{HG}$ and it was in the third-ranking. The base flow alpha (ALPHA_BF) is the parameters related to baseflow recession coefficient factor that sensitive for P-T and P-M (Fig. 4).

The GW DELAY (time for water in the soil to become recharge), ALPHA BNK (baseflow alpha factor for bank storage) and the geomorphology input of $\mathrm{CH}_{-} \mathrm{K} 2$ (hydraulic conductivity in main channel alluvium) were ranked in the top significant sensitive parameters. It was also shown that the soil input parameters, SOL_AWC (water capacity of soil layer) and SOL_BD (moist bulk density) show insignificant to the three PET methods, while the SOL_K (saturated hydraulic conductivity) was insensitive for HG. While the RCHRG_DP (fraction of deep aquifer percolation), GW_REVAP (coefficient of movement shallow aquifer water to root zone), SHALLST (initial water level of shallow aquifer) and DEEPST (initial water level of deep aquifer) was assessed as insignificant groundwater parameter. In addition, the OV_N (Manning's coefficient of surface roughness) for surface flow estimation was more sensitive of the geomorphology HRUs characteristics with $\mathrm{HG}$ and no significant with P-T and P-M.
Uncertainty and calibration performance: The SWAT-CUP automatically calculate the performance statistic comparing observed data with the best simulation. The performance obtained by SUFI-2 was based on the best value optimized for each parameter of the iteration and defined a new value range for each selected parameters in each simulation band. The best model performance was evaluated by using the R2, NSE and PBIAS values while $\mathrm{p}$-factor and $\mathrm{r}$-factor results through relative measurements and simulations coverage, were used to show the model prediction uncertainty.

Figure 5 shows the observed and simulation flow hydrographs from the year 1985-2016 with the statistical criteria for HG, P-T and P-M methods. The results of R2, NSE and PBIAS values showed that a very good calibration and good performance during validation period over the entire catchment between observed and simulated streamflow at the watershed outlet by using the three PET methods. The comparison exposed that among the three PET method, the HG performed better in term of R2 and NSE. It was found for the HG methods, achieved NSE value of 0.85 and 0.77 in the calibration and validation periods, respectively. Moriasi et al. (2015) recommended the model with NSE more than 0.80 considers excellent and the values between 0.7-0.80 were good for monthly response output (Table 1). While for P-T and P-M prediction, the model NSE are 0.74 and 0.78 for calibration and 0.74 and 0.73 for validation, respectively.

The p-factor of 82,74 and $78 \%$ at the $95 \%$ prediction uncertainty level in the calibration at monthly time-step while using HG, P-T and P-M, respectively shows the high percentage of observed data bracketed by the 95PPU. Furthermore, the r-factor values of uncertainties degree found for the best simulation to be $0.75,0.92$ and 0.90 were $<1.5$ as recommended by Abbaspour et al. (2015). However, the $\mathrm{p}$-factor calculated with SUFI-2 yielded unsatisfactory outcomes in the validation period where the value obtained $<0.5$ where 

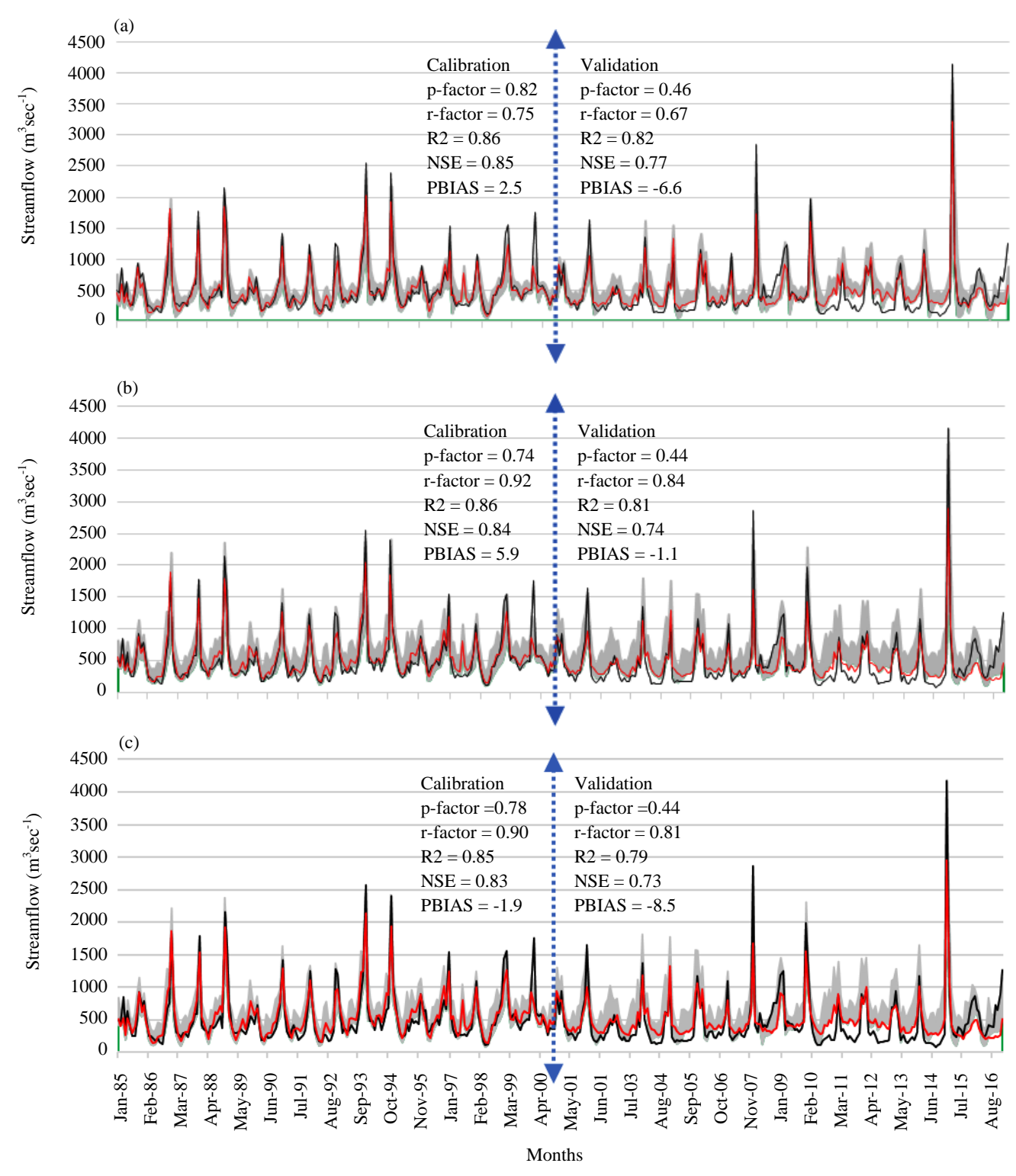

Fig. 5(a-c): The best model performance with 95PPU SWAT-CUP illustrations of the three PET methods for monthly output calibration (1985-2001) and validation (2001-2016) periods at the Guillemard Bridge station

the scholars proposed acceptable value more than 0.7 . Figure 5 shows clearly the observed flows were bracketed within the 95PPU band below than 50\% during calibration compared more than $70 \%$ in the calibration period. Figures also show the low of observed baseflow in the years 2010-2014 and the simulation far away to reach the peak as observed, especially in December, 2007 and 2014. These could happen influenced by information uncertainty and inconsistency in weather data or geography. There are also recorded big flood in whole Kelantan catchment in year 2014 that have possibility altered physically the surface of landscape and soil properties. The SWAT-CUP used various parameter with their vary ranges in calibration can affect the overall streamflow simulation including the base and peak flow (Lee et al., 2018).

\section{CONCLUSION}

The model performance for the flow simulation at the Guillemard Bridge station has proven the effectiveness of the SWAT Model and representing practical sensitive parameters by automatically calibration using SWAT-CUP. The SWAT-CUP with SUFI-2 algorithm was successfully identified as the most significant sensitive parameters for the three PET 
methods and considered to be applicable for Guillemard Bridge Watershed. The parameters included for surface runoff, lateral flow, channel and soil properties to be updated in the SWAT Model. The sensitivity analysis discovered the sensitive parameter ranking varies with different PET estimation method. However, the most significance sensitive parameters $(\mathrm{CN} 2, \mathrm{SOL} Z \mathrm{Z}$ and LAT_TIME) kept the same ranks due to the same climate and topography data.

Conclusions that could be resulting from this study: the significant of the parameter sensitivity analysis, which are considered to have an influence on streamflow were show different ranking for different PET methods in the Guillemard Bridge Watershed. However, the results obtained show a good agreement between the three PET methods, the streamflow simulations is most influenced by the parameters such as CN2, SOL_Z, LAT_TIME, GW_DELAY and CH_K2. SOL_K show more sensitive while using P-T and ${ }^{-}$- $-M$ and less sensitive in $\mathrm{HG}$ method. In contra, ESCO more sensitive with HG than the P-M and P-T methods.

The results have confirmed among the sensitive parameters, the GWQMN was only sensitive while P-M method was selected in the SWAT Model. The SUFI-2 results show that $\mathrm{HG}$ method has larger uncertainties than the P-M and P-T for streamflow simulation. The uncertainty for HG, P-T and P-M were 25,8 and $10 \%$ during calibration while during calibration were 33,16 and $19 \%$, respectively. HG has high uncertainty because the PET calculation depends only onair temperature data. Therefore, HG option should be less preferable unless there are incomplete the solar radiation, relative humidity or wind speed data.

Although, the NSE, R2, PBIAS, p-factor and r-factor results value of $\mathrm{HG}, \mathrm{P}-\mathrm{T}$ and $\mathrm{P}-\mathrm{M}$ were relatively small, the SWAT Model with option P-T method was considered more accurately reflected the smaller PBIAS and higher $\mathrm{r}$-factor than $\mathrm{HG}$ and P-M methods.

Overall, the performance and uncertainty result for each PET methods, the SWAT Model with P-T methods performed a better Rainfall-runoff Model for the Kelantan river basin. The sensitivity findings should make an important contribution to the field of data collections and verifications for the hydrological modeling by demonstrating the significant and insignificant input parameters. In future, the performance of the SWAT Model could be enhanced by multiple gauge calibration and the computed ET should also be validated at each sub-basin because it is one of the main water balance components of a basin catchment.

\section{ACKNOWLEDGEMENTS}

The researcher are thankful for the scholarship and the financial support from the Public Service Department Malaysia. The researcher appreciates those people and agencies that assisted in accessing research data and information. The researchers would like to acknowledge the Universiti Tenaga Nasional (UNITEN) grant, BOLD2025 with reference number 10436494/B/2019136.

\section{REFERENCES}

Abbaspour, K.C, 2015. SWAT-CUP 2012: SWAT calibration and uncertainty programs-A user manual. Eawag: Swiss Federal Institute of Aquatic Science and Technology, Dubendorf, Switzerland. https:// swat.tamu.edu/media/114860/usermanual_swatcup. pdf

Abbaspour, K.C., E. Rouholahnejad, S. Vaghefi, R. Srinivasa, H. Yang and B. Kloved, 2015. A continental-scale hydrology and water quality model for Europe: Calibration and uncertainty of a high-resolution large-scale SWAT Model. J. Hydrol., 524: 733-752.

Abbaspour, K.C., S.A. Vaghefi and R. Srinivasan, 2018. A guideline for successful calibration and uncertainty analysis for soil and water assessment: A review of papers from the 2016 International SWAT conference. Water, Vol. 10, No. 1. 10.3390/w10010 006

Alemayehu, T., A.V. Griensven and W. Bauwens, 2015. Evaluating CFSR and WATCH data as input to SWAT for the estimation of the potential evapotranspiration in a data-scarce Eastern-African catchment. J. Hydrol. Eng., Vol. 21, No. 3. 10.1061/(ASCE)HE.1943-5584. 0001305

Arnold, J., J. Kiniry, R. Srinivasan, J. Williams, E. Haney and S. Neitsch, 2012. Soil \& water assessment tool: Input/output documentation. Report TR-439, Texas Water Resources Institute, Forney, Texas, USA.

Ayivi, F. and M.K. Tha, 2018. Estimation of water balance and water yield in the Reedy Fork-Buffalo Creek Watershed in North Carolina using SWAT. Int. Soil Water Conserv. Res., 6: 203-213.

Bekele, D., T. Alamirew, A. Kebede, G. Zeleke and A.M. Melesse, 2019. Modeling climate change impact on the Hydrology of Keleta watershed in the Awash River Basin, Ethiopia. Environ. Model. Assess., 24: 95-107.

Chunn, D., M. Faramarzi, B. Smerdon and D.S. Alessi, 2019. Application of an integrated SWATMODFLOW Model to evaluate potential impacts of climate change and water withdrawals on groundwater-surface water interactions in WestCentral Alberta. Water, Vol. 11, No. 1. 10.3390/w11010110

Dakhlalla, A.O. and P.B. Parajuli, 2019. Assessing model parameters sensitivity and uncertainty of streamflow, sediment and nutrient transport using SWAT. Inf. Process. Agric., 6: 61-72.

Dinpashoh, Y., S. Jahanbakhsh-Asl, A.A. Rasouli, M. Foroughi and V.P. Singh, 2019. Impact of climate change on potential evapotranspiration (case study: West and NW of Iran). Theor. Applied Climatol., 136: 185-201. 
Efthimiou, N., S. Alexandris, C. Karavitis and N. Mamassis, 2013. Comparative analysis of reference evapotranspiration estimation between various methods and the FAO56 Penman-Monteith procedure. Eur. Water, 42: 19-34.

Her, Y., J. Frankenberger, I. Chaubey and R. Srinivasan, 2015. Threshold effects in HRU definition of soil and water assessment tool. Trans. ASABE., 58: 367-378.

Kannan, N., C. Santhi, M.J. White, S. Mehan, J.G. Arnold and P.W. Gassman, 2019. Some challenges in Hydrologic model calibration for large-scale studies: A case study of SWAT Model application to Mississippi-Atchafalaya River Basin. Hydrol., Vol. 6, No. 1. 10.3390/hydrology6010017

Khalid, K., M.F. Ali, N.F.A. Rahman, M.R. Mispan, S.H. Haron, Z. Othman and M.F. Bachok, 2016. Sensitivity analysis in watershed model using SUFI-2 algorithm. Procedia Eng., 162: 441-447.

Lee, J., J. Kim, W.S. Jang, K.J. Lim and B.A. Engel, 2018. Assessment of base flow estimates considering recession characteristics in SWAT. Water, Vol. 10, No. 4. $10.3390 / \mathrm{w} 10040371$

Ligaray, M., H. Kim, S. Sthiannopkao, S. Lee, K.H. Cho and J.H. Kim, 2015. Assessment on hydrologic response by climate change in the Chao Phraya River Basin, Thailand. Water, 7: 6892-6909.

Maharjan, G.R., Y.S. Park, N.W. Kim, D.S. Shin and J.W. Choi et al., 2013. Evaluation of SWAT sub-daily runoff estimation at small agricultural watershed in Korea. Front. Environ. Sci. Eng., 7: 109-119.

Megersa, T., D. Nedaw and M. Argaw, 2019. Combined effect of land use/cover types and slope gradient in sediment and nutrient losses in Chancho and Sorga sub watersheds, East Wollega Zone, Oromia, Ethiopia. Environ. Syst. Res., Vol. 8, No. 1. 10.1186/s40068-019-0151-3

Moriasi, D.N., M.W. Gitau, N. Pai and P. Daggupati, 2015. Hydrologic and water quality models: Performance measures and evaluation criteria. Trans. ASABE., 58: 1763-1785.

Narsimlu, B., A.K. Gosain, B.R. Chahar, S.K. Singh and P.K. Srivastava, 2015. SWAT Model calibration and uncertainty analysis for streamflow prediction in the Kunwari River Basin, India, using sequential uncertainty fitting. Environ. Processes, 2: 79-95.

Neitsch, S.L., J.G. Arnold, J.R. Kiniry and J.R. Williams, 2011. Soil and water assessment tool, theoretical documentation version 2009. Texas Water Resources Institute Technical Report No. 406, Septem ber 2011 , Temple, TX.
Paul, M. and M. Negahban-Azar, 2018. Sensitivity and uncertainty analysis for streamflow prediction using multiple optimization algorithms and objective functions: San Joaquin Watershed, California. Model. Earth Syst. Environ., 4: 1509-1525.

Qi, J., X. Zhang, S. Lee, G.E. Moglen, A.M. Sadeghi and G. W. McCarty, 2009. A coupled surface water storage and subsurface water dynamics model in SWAT for characterizing hydroperiod of geographically isolated wetlands. Adv. Water Resour., Vol. 131,

Querner, E.P. and M. Zanen, 2013. Modelling water quantity and quality using SWAT: A case study in the Limpopo River basin, South Africa. Alterrareport 2405, Wageningen Environmental Research (Alterra), Wageningen, Netherlands. https:/library.wur.nl/WebQuery/wurpubs/437195

Samadi, S., D.L. Tufford and G.J. Carbone, 2017. Assessing parameter uncertainty of a semi distributed Hydrology model for a shallow aquifer dominated environmental system. JAWRA. J. Am. Water Resour. Assoc., 53: 1368-1389.

Sun, L., L. Yang, L. Hao, D. Fang, K. Jin and X. Huang, 2017. Hydrological effects of vegetation cover degradation and environmental implications in a semiarid temperate Steppe, China. Sustainability, Vol. 9, No. 2. 10.3390/su9020281

Tan, M.L., D.L. Ficklin, A.L. Ibrahim and Z. Yusop, 2014. Impacts and uncertainties of climate change on streamflow of the Johor River Basin, Malaysia using a CMIP5 General Circulation Model ensemble. J. Water Clim. Change, 5: 676-695.

Thavhana, M.P., M.J. Savage and M.E. Moeletsi, 2018. SWAT Model uncertainty analysis, calibration and validation for runoff simulation in the Luvuvhu River catchment, South Africa. Phys. Chem. Earth Parts A. B. C., 105: 115-124.

Vigiak, O., S. Lutz, A. Mentzafou, G. Chiogna, Y. Tuo, B. Majone and R. Kumar, 2018. Uncertainty of modelled flow regime for flow-ecological assessment in Southern Europe. Sci. Total Environ., 615: 1028-1047.

Yacoub, C. and A.P. Foguet, 2012. Slope effects on SWAT Modeling in a mountainous Basin. J. Hydrol. Eng., 18: 1663-1673.

Zhang, S., W. Fan, Y. Li and Y. Yi, 2017. The influence of changes in land use and landscape patterns on soil erosion in a watershed. Sci. Total Environ., 574: 34-45.

Zhao, P., H. Lu, H. Yang, W. Wang and G. Fu, 2019. Impacts of climate change on hydrological droughts at basin scale: A case study of the Weihe River Basin, China. Quat. Int., 513: 37-46. 